\title{
ACCOUNTING STUDENTS' LIKELIHOOD OF COMPLIANCE WITH TAX PREPARATION STANDARDS
}

\author{
Edward Monsour, JD, CPA \\ Rafik Z. Elias, $D B A, C P A$ \\ Cheryl A. Cruz, JD, CPA \\ California State University, Los Angeles \\ Los Angeles, CA
}

\begin{abstract}
The current study examines the likelihood that accounting students will comply with the AICPA's enforceable Statements on Standards for Tax Services (SSTS). A sample of 224 accounting students completed a questionnaire including SSTS scenarios. Overall, a significant portion of accounting students was not likely to follow the standards on five out of six scenarios. A group of students that received specific instruction in SSTS was not more likely to comply with them compared to a group that did not learn the standards. In addition, there were differences based on gender, age and class grade in the likelihood of compliance.
\end{abstract}

Accounting professionals have faced increasing pressures from regulators and the public in the wake of corporate accounting scandals a few years ago. The American Institute of Certified Public Accountants (AICPA) has emphasized the need for accountants to focus on their responsibilities to the public. In the areas of tax preparation and tax planning, these responsibilities are framed within the framework of Statements on Standards for Tax Serwices (SSTS). These standards, effective since 2000 , represent enforceable codes of conduct by CPAs in tax return preparation and tax planning.

The purpose of this paper is to investigate accounting students' likelihood of following these tax standards. Accounting students represent future CPAs and their perception of tax standards, after being exposed to them, can give an insight into their perception of the importance of such standards. Hume, Larkins, and Iyer (1999) investigated tax professionals' compliance with Statements on Responsibilities in Tax Practice (SRTP), which were advisory in nature and were superseded by the enforceable SSTS. However, in Hume et al. (1999), one possible limitation of the results was that CPAs may not have been familiar with SRTP since they were only suggested guidelines. In the current study, accounting students are divided into two groups: One group received specific instruction on SSTS and another group did not. The study examines the likelihood of compliance with SSTS and investigates whether demographic factors such as gender, age and class grade have an effect on students' compliance. 
The paper is organized as follows: After this introduction is a background on the concepts of tax preparation along with a discussion of ethics and an examination of SSTS. This is followed by an explanation of the research design and sample selection. The results are presented next followed by discussion and implications for accounting education and the accounting profession.

\section{Background}

\section{Tax Preparation and Ethics}

A significant segment of CPAs is involved in tax preparation of individual tax returns and tax planning. Approximately $55 \%$ of all federal income tax returns and even greater percentages of complex tax returns are prepared by tax professionals. The cost exceeds $\$ 11$ billion annually (Yetmar \& Rioux, 2004). Even with increasing complexities of tax laws and increased demand for tax preparation, CPAs face competition from accountants without the CPA designation, enrolled agents, tax-preparation chains and software programs (Fisher, 1994). This increasing competition from less-expensive sources presents CPAs with a dilemma in determining their level of conservatism.

In providing tax preparation and planning services, CPAs attempt to satisfy many constituents such as clients, employers, professional organizations and government agencies. Given these constituents with different goals and risk preferences, it is not surprising for CPAs to face ethical conflicts during their careers (Yetmar, 1997). CPAs are confronted with ethical dilemmas especially when there is client pressure to adopt overly aggressive tax positions (Hume et al., 1999; Cruz, Shafer \& Strawser, 2000). Finn, Chonk, and Hunt (1988) noted this problem in an earlier survey of CPA tax preparers where almost half of them indicated their biggest problem was clients' proposals to alter tax liability and/or tax fraud. Almost half of the respondents felt that CPAs outside their firms often engaged in unethical activities.

In facing these ethical challenges, CPAs must sometimes balance competing interests. Taxpayers and the IRS have different expectations of CPAs. The IRS maintains that CPAs should have loyalty to the U.S. tax system and act as government agents (Brody \& Masselli, 1996). On the other hand, research shows that many taxpayers are ambivalent about whether tax cheating is morally wrong and are often willing to play the audit lottery (i.e., adopting aggressive or even fraudulent positions based on a low audit probability) (Kaplan \& Reckers, 1985; Westat, 1980). Yetmar and Eastman (2000) noted that taxpayers expect CPAs to minimize their clients' tax liability and be the clients' advocate. Schisler (1995) found that taxpayers were generally more aggressive than preparers on every scenario presented and Schisler (1994) concluded that preparers adhered to the aggressive tendencies of their clients.

In order for the IRS to illustrate the importance of its position, it has increased penalties on tax preparers in recent years. Yetmar and Rioux (2004) estimated that a quarter of all tax preparers would be assessed for some type of preparer 
penalty during their career. Brody and Masselli (1996) criticized the IRS position and noted that it failed to consider the possibility that two or more tax positions, even though they differ in their level of aggressiveness, may still meet the good faith criterion for recommending a position.

Erard (1993) found that CPAs and lawyers were more likely to condone aggressive reporting activities as well as recommend tax shelters to their clients compared to nonlicensed preparers. Research regarding the impact of sanctions on CPAs' behavior has reached mixed conclusions. For example, Reckers, Sanders, and Wyndelts (1991) found that preparer penalties were effective in reducing CPAs aggressiveness in signing returns. On the other hand, Cuccia (1994) found preparer sanctions increased the effort by CPAs in the engagement but did not have an effect on aggressiveness.

Some research has attempted to determine factors influencing tax preparers' ethical decisions. Cruz et al. (2000) found that tax practitioners' behavior was consistent with five ethical philosophies: Moral equity, contractualism, utilitarianism, relativism, and egoism. Another study found that expert tax preparers seemed to be most influenced by personal integrity and professional ethics when confronted with clients' desires in tax matters (Jackson, Milliran \& Toy, 1988).

In dealing with potential ethical conflicts in tax preparation, the AICPA requires members to act with integrity and maintain the public trust. The SSTS illustrate the CPAs' commitment to meet their responsibilities to the public.

\section{SSTS and Responsibilities}

Between 1964 and 1977, the AICPA issued SRTP. They were guidelines that helped CPAs recognize their ethical obligation to the public. They dealt with issues such as knowledge of an error in a filed tax return, use of estimates, and CPAs taking aggressive tax positions that will circumvent tax audits. The SRTP were voluntary standards. However, they became de facto enforcement standards with courts, the IRS, state accountancy boards and other professional organizations relying on them as accepted professional conduct in tax practice (Swails, 2000).

In 2000, the AICPA replaced SRTP with SSTS. The SSTS differ from the SRTP in one important way. The SSTS are explicitly enforceable professional standards. Members of the AICPA who do not adhere to SSTS are subject to sanctions. Although other tax practice standards exist, most notable Treasury Department Circular 230 and penalty provisions of the Internal Revenue Code (IRC), they are limited in that (1) they do not provide the depth of guidance contained in the SSTS, and (2) they may be considered to take an unrealistic or oversimplified view of the complexities of tax practice (Swails, 2000).

The SSTS were written in as simple and objective a manner as possible. In terms of content, the SSTS mirror the old SRTP: The name, number, and substance of each statement remain essentially the same. The current study uses the SSTS to investigate accounting students' likelihood of compliance. 


\section{Accounting Students and Ethics}

Prior research has shown that despite widespread efforts by practitioners and educators to encourage greater emphasis on ethics in accounting education, there has been minimal coverage of ethics in the accounting curriculum (e.g. Thompson, McCoy \& Wallestad, 1992). However, a more recent national survey by Mastracchio (2005) found that half of the Colleges of Business offered a separate course in business ethics. In addition, $90 \%$ of the surveyed schools noted that protecting the public interest was covered in the Auditing course.

Although research has investigated accounting students' ethical reasoning in general accounting settings, little research has specifically examined tax settings. Since many accounting students will be involved with tax preparation and planning, whether as CPAs in public practice or as CMAs in industry, it is important to understand their perception of tax preparation standards and the likelihood of compliance with such standards.

In a literature review, Borkowski and Ugras (1998) identified several factors (e.g. gender, age and class grade) that can affect accounting students' ethical reasoning with mixed conclusions. In a tax context, Grasso and Kaplan (1998) investigated gender and age differences in tax ethics perception among accounting students. The results showed that females tended to believe more strongly than males that evading taxes was immoral. Contrary to most previous ethics research regarding age, Grasso and Kaplan (1998) found that younger students ( $<25$ years old) perceived evading taxes as more immoral compared to older nontraditional students. In several scenarios, students believed actions to be ethical, even though they believed these actions conflicted with the AICPA code of conduct. Fallan (1999) also investigated gender in a tax context. The results showed that females reconsidered their position on tax ethics issues more often than males.

Some research has also investigated the extent of tax knowledge and exposure on ethical decision making. Eriksen and Fallan (1996) examined whether a tax course had an effect on accounting students' perception of their own tax evasion, their attitude towards other people's tax evasion and the students' perception of tax fairness. In a pre- and post-test design, the authors concluded that increased tax knowledge resulted in accounting students viewing their own and others' tax evasion as more serious. Students' perception of tax fairness also increased after the course. Similar results were reported in Fallan (1999). The current study examines gender, age, class grade and specific exposure to SSTS on accounting students' likelihood of compliance with professional standards. The current study does not attempt to form conclusions about tax practitioners' likelihood of compliance with standards, or use students as surrogates for tax practitioners. Rather, it examines the accounting student population, at this early stage of career development.

\section{Sampling}

\section{Research Method}

The sample for this study consisted of accounting students in a large AACSBaccredited public university. The students were enrolled in individual and corporate 
tax classes. The survey was administered two weeks before the end of the term to allow students to learn all the necessary tax information. Overall, nine sections were surveyed over a six-month period. These sections were taught by four different instructors. The voluntary survey took about 10-15 minutes to complete and students were assured of confidentiality. A total of 237 responses were received. After eliminating responses with missing information, the useable sample was 224 responses. The students were divided into two groups: One group (four sections, 88 students) received detailed classroom instruction on SSTS. The other group (five sections, 136 students) did not receive instruction on SSTS. The purpose of this split is to investigate if specific instruction on enforceable standards would have an effect on students' likelihood of following them.

\section{Measures}

The survey used in this study consisted of a questionnaire and demographic questions. The questionnaire was adapted from Hume et al. (1999). In that study, the authors developed six scenarios that mirrored the content of SRTP at that time. They surveyed CPAs involved in tax preparation as well as nonlicensed preparers to investigate the likelihood of following the SRTP guidelines. The results indicated that the majority of CPAs followed the SRTP in most of the issues more often than nonlicensed preparers. However, a statistically significant number of CPAs do not follow the SRTP on half the issues and did not follow them more often than nonlicensed preparers on these issues. Since the SSTS are identical to the SRTP in content, the same scenarios from Hume et al. (1999) were used in this study. The scenarios are presented in the Appendix. They deal with issues such as knowledge of an error, inquiries, yielding to client pressure and the appropriateness of using estimates among others.

\section{Research Results}

The sample's demographic characteristics are presented in Table 1. The table shows that most of the sample consisted of females and undergraduate students. In order to investigate whether specific education in SSTS has an impact on students' likelihood to follow them, both groups of respondents were compared on each scenario using the Chi-Square test. The results indicate no statistically significant differences between the two groups on any of the scenarios. The results are reported in Table 1.

A test of proportions was used to examine the likelihood of accounting students not following SSTS. In general, the great majority of students tended to follow SSTS in scenario 1. However, significant portions of students did not follow the standards in all other scenarios. A significant portion of students did not follow SSTS in scenario 2, regarding the use of estimates. SSTS specifically prohibits CPAs from reporting an estimated amount as an exact amount. Overall, 34\% of the students did not follow the standards in scenario 2. In scenario 3, almost $18 \%$ of the students did not follow the standards, while the percentages of non- 
compliance for scenarios 4,5 and 6 were $16 \%, 14 \%$ and $22 \%$ respectively. These results are alarming because they indicate that a significant portion of future tax preparers do not follow SSTS.

Table 1

Demographics and Accounting Students' Compliance with SSTS

\section{Panel A: Demographic Characteristics (N)}

$\begin{array}{llr}\text { Gender: } & \text { Male } & 72 \\ & \text { Female } & 152 \\ & & \\ \text { Age: } & <25 \text { years old (traditional) } & 101 \\ & 25 \text { years or }>\text { (nontraditional) } & 123 \\ \text { Class Grade: } & \text { Undergraduate } & 150 \\ & \text { Graduate } & 74\end{array}$

Panel B: Scenario

\begin{tabular}{lccc}
$\begin{array}{c}\text { \% complying } \\
\text { With SSTS } \\
\text { (Overall) } \\
\text { (N=224) }\end{array}$ & $\begin{array}{c}\text { \% complying } \\
\text { with SSTS } \\
\text { (after education) } \\
\text { (N=88) }\end{array}$ & $\begin{array}{c}\text { \% complying } \\
\text { with SSTS } \\
\text { (without education) } \\
\text { (N=136) }\end{array}$ \\
\hline 1. & $95.5 \%$ & $96.5 \%$ & $94.8 \%$ \\
2. & $66 \% \%^{* * *}$ & $62.5 \%$ & $68.3 \%$ \\
3. & $82.5 \% \%^{* * *}$ & $78.4 \%$ & $85.2 \%$ \\
4. & $84.8 \% * * *$ & $85.2 \%$ & $84.5 \%$ \\
5. & $86.6 \% * * *$ & $88.6 \%$ & $85.2 \%$ \\
6. & $77.7 \% * * *$ & $83 \%$ & $74.3 \%$
\end{tabular}

$* * * \mathrm{p}<., 01$

probability that significant respondents do not follow SSTS

In order to investigate the impact of demographic factors on the likelihood of following SSTS, logistic regression (Logit) was used with the responses of compliance or noncompliance as the dependent variable and the demographics as the independent variables for each scenario separately. Due to the fact that explanatory variables such as age, gender and class grade might be correlated, correlation analysis was conducted between these variables. The results indicated no correlation between gender and age $(r=-.28 ; p=.67)$ or between gender and class grade $(\mathrm{r}=.11 ; \mathrm{p}=.08)$. However, there was a statistically significant correlation between age and class grade $(r=.19 ; \mathrm{p}<.01)$. Therefore, the following 
results regarding age and grade should be interpreted in light of their correlation. The significant results are reported in Table 2.

Table 2

Demographic Differences between Accounting Students

\begin{tabular}{|c|c|c|c|c|c|c|}
\hline \multirow{2}{*}{\multicolumn{2}{|c|}{$\begin{array}{l}\text { Scenario } \\
\text { Gender }\end{array}$}} & \multicolumn{4}{|c|}{ Percentage Complying with SSTS } & \\
\hline & & & Age & & Class Grade & \\
\hline \multicolumn{2}{|l|}{1.} & & & & $\begin{array}{l}\text { Undergraduate } \\
\text { Graduate }\end{array}$ & $\begin{array}{l}98 \% * * * \\
90.5 \% * * *\end{array}$ \\
\hline \multicolumn{7}{|l|}{2.} \\
\hline \multirow[t]{2}{*}{3.} & & & Traditional & $90.1 \% * *$ & Undergraduate & $86.6 \% * *$ \\
\hline & & & Nontraditional & $76.4 \% * *$ & Graduate & $74.3 \% * *$ \\
\hline \multirow[t]{2}{*}{4.} & & & & & Undergraduate & $92 \% * * *$ \\
\hline & & & & & Graduate & $70.2 \% * * *$ \\
\hline \multirow[t]{2}{*}{5.} & Male & $79.1 \% * *$ & & & & \\
\hline & Female & $90.1 \% * *$ & & & & \\
\hline \multirow[t]{2}{*}{6.} & & & Traditional & $71.3 \% * *$ & Undergraduate & $81.4 \% * *$ \\
\hline & & & Nontraditional & $83 \% * *$ & Graduate & $70.3 \% * *$ \\
\hline
\end{tabular}

Traditional $=<25$ years old

Nontraditional $=25$ years or $>$

$* * * \mathrm{p}<.01$

$* * p<.05$

The results indicate significant differences based on gender in scenario 5 only (regarding inquiry about information that appears incorrect). In that case, the proportion of females likely to follow SSTP $(90.1 \%)$ was significantly higher than males $(79.1 \%)$. There were no significant differences on any other scenarios based on gender.

Regarding age differences, there were significant differences in scenarios 3 and 6 . In scenario 3 (dealing with notifying the client of an error in a previous return), younger students were more likely to follow SSTP (90.1\%) compared to older students (76.4\%). However, in scenario 6 (dealing with changing an item under client pressure), older students were more likely to follow SSTP $(83 \%)$ compared to younger students $(71 \%)$.

Class grade differences were also significant. In scenario 1 (dealing with correcting an error in a current return), undergraduate students were more likely to 
follow SSTS (98\%) compared to graduate students (90.5\%). In scenarios 3, 4 and 6 , similar differences emerged with undergraduate students more likely to comply with SSTP compared to graduate students.

\section{Discussion and Implications}

The current study's results provide several conclusions about the likelihood of accounting students following required tax standards. In general, with the exception of scenario 1 (dealing with correcting an error in a current return), a significant portion of accounting students were not likely to comply with SSTS. The results are alarming since many of these students will be CPAs in public practice or CMAs in industry, both involved with tax preparation and planning. The results of this study, however, can not be directly compared to Hume et al. (1999) regarding CPAs and other tax preparers because at the time Hume et al. (1999) was conducted, SRTP were advisory guidelines, while current SSTS are enforceable standards.

More alarming is the conclusion that specific education about SSTS did not influence students' likelihood of following them in tax preparation. These results conflict with Grasso and Kaplan (1998) who found that tax students exposed to professional ethics and responsibilities exhibited higher ethical standards. The results also conflict with Ward and Ward (1996) who found that students receiving specific instructions in the AICPA Code of Conduct were more likely to follow it compared to students who did not receive such training. It is possible, as Grasso and Kaplan (1998) indicated, that some students believe that a particular behavior is ethical while professional standards consider it unethical. The extent of this possibility can be the subject of future research regarding the enforceable SSTP.

Regarding demographic factors, there were minor differences based on gender and only on scenario 5 were females more likely to comply with SSTS than males. Results regarding age were mixed since in scenario 3 , younger students were more likely to comply than older students while in scenario 6 , the opposite results appeared. The evidence was stronger in favor of class grade differences in likelihood of compliance. In four out of six scenarios, undergraduate students were more likely to comply with standards compared to graduate students. This finding is also alarming since graduate students possess more accounting and tax education.

The results of this study indicate that accounting instructors must emphasize ethics in the classroom in a more productive manner. Since there was no impact of extra education on standards, perhaps accounting instructors should emphasize the reasons for such standards. Instructors should emphasize tax preparers' responsibilities to both clients and the IRS and explain the purpose of each standard separately, rather than their enforceability alone. A future study can examine students' likelihood of following SSTS before and after the class, after extensive discussion of the reasons and ethics of such standards.

The study also has implications for accounting practitioners. Ahadiat and Mackie (1993) argued that new entrants in the accounting profession were se- 
lected from the pool of university graduates. The authors argued that recruiters should consider ethics in making hiring decisions. The current study helps future employers in two ways: It identifies certain groups of accounting students that can potentially have different ethical characteristics compared to others. It also shows the compliance likelihood of future employers with professional standards, just before they enter the profession. Based on the study's findings, employers should make an effort to emphasize tax compliance among their new recruits.

\section{References}

Ahadiat, N., \& Mackie, J. (1993). Ethics education in accounting: An investigation of ethics as a factor in the recruiting decisions of public accounting firms. Journal of Accounting Education, 12, 243-257.

Borkowski, S. C., \& Ugras, Y. J. (1998). Business students and ethics: A meta-analysis. Journal of Business Ethics, 17, 1117-1127.

Brody, R. G., \& Masselli, J. J. (1996). Tax preparers: Whose team are they on? National Public Accountant, 41, 18.

Cruz, C. A., Shafer, W. E., \& Strawser, J. R. (2000). A multidimensional analysis of tax practitioners' ethical judgments. Journal of Business Ethics, 24, 223-244.

Cuccia, A. D. (1994). The effects of increased sanctions on paid preparers: Integrating economic and psychological factors. The Journal of the American Taxation Association, 16, 41-66.

Erard, B. (1993). Taxation with representation: An analysis of the role of tax practitioners in tax compliance. Journal of Public Economics, 163-197.

Eriksen, K., \& Fallan, L. (1996). Tax knowledge and attitudes towards taxation: A report on a quasi-experiment. Journal of Economic Psychology, 17, 387-402.

Fallan, L. (1999). Gender exposure to tax knowledge, and attitudes towards taxation; An experimental approach. Journal of Business Ethics, 18, 173-184.

Finn, D. W., Chonko L. B., \& Hunt, S. D. (1988). Ethical problems in public accounting: The view from the top. Journal of Business Ethics, 7, 605-615.

Fisher, A. B. (1994). Finding the right tax advisor. Fortune, 129, 77-80.

Grasso, L. P., \& Kaplan, S. E. (1998). An examination of ethical standards for tax issues. Journal of Accounting Education, 16, 85-100.

Hume, E. C., Larkins, E. R., \& Iyer, G. (1999). On compliance with ethical standards in tax return preparation. Journal of Business Ethics, 18, 229-238. 
Jackson, B. R., Milliron, V. C., \& Toy, D. R. (1988). Tax practitioners and the government. Tax Notes 41, 333-341.

Kaplan, S. E., \& Reckers, P. M.(1985). A study of tax evasion judgments. National Tax Journal, 97-102.

Mastracchio, N. J., Jr. (2005). Teaching CPAs about serving the public interest. The CPA Journal, 75,6 .

Reckers, P., Sanders, D., \& Wyndelts, R. (1991). An empirical investigation of factors influencing tax practitioner compliance. The Journal of the American Taxation Association, 30-46.

Schisler, D. L. (1995). Equity, aggressiveness, consensus: A comparison of taxpayers and tax preparers. Accounting Horizons, 9, 76-87.

Schisler, D. L. (1994). An experimental examination of factors affecting tax preparers' aggressiveness - a prospect theory approach. The Journal of American Taxation Association, 16, 124-142.

Swails, J. E. (2000). New standards for tax practice. Journal of Accountancy, 190, 7986.

Thompson, J. H., McCoy, T. L., \& Wallestad, D. A. (1992). The incorporation of ethics into the accounting curriculum. Advances in Accounting, 10, 91-103.

Ward, S. P., \& Ward, D. R. (1996). The code of professional conduct: Instructional impact on accounting students' ethical perceptions and attitudes. Journal of Education for Business, 71, 147-151.

Westat, Inc. (1980). Individual income tax compliance factors study qualitative research. (Prepared for the Internal Revenue Service).

Yetmar, S. A., \& Rioux, J. (2004). Components of the AICPA's statements on standards for tax services. The CPA Journal, 74, 64-66.

Yetmar S. A., \& Eastman, K. K. (2000). Tax practitioners' ethical sensitivity: A model and empirical examination. Journal of Business Ethics, 26, 271-288.

Yetmar, S. A., (1997). Recognizing SRTP violations in return preparation. The Tax Adviser, 28, 654-658. 


\section{Appendix}

\section{SSTS Scenarios adapted from Hume et al. (1999)}

1. You assured your client early in the engagement that a particular expenditure would be deductible on his income tax return. After preparing the client's return, but before mailing it, you discover that a Revenue Ruling clearly disallows a deduction for the expenditure in question. After some further investigation, you believe that the Revenue Ruling is a correct interpretation of the law and that there is no reasonable basis for taking the deduction. Nonetheless, you do not think the item will be detected by the IRS. You have basically two choices: (1) You could ignore the Revenue Ruling and mail the return. (2) You could notify the client of the mistake and correct the return.

Would you notify the client of the mistake and correct the return?

$$
\text { Yes }
$$$$
\text { No }
$$

2. You client incurred an expense which is deductible on her tax return. However, the exact dollar amount is not known and must be estimated. For this type of expense, the tax law allows the use of estimates. You have basically two choices: (1) You can present the estimated estimate (e.g. $\$ 1,983$ ) . (2) You can present the estimated item in the return as a rounded amount (e.g. $\$ 2,000$ ) .

Would you present the estimated item as a rounded amount (e.g. $\$ 2,000)$ ? Yes No

3. In preparing your client's income tax return this year, you discover that the return prepared last year contained a material error. (Assume you are not acquainted with the person who prepared that return last year). In particular, a $\$ 1,000$ deduction was listed as a $\$ 3,000$ deduction. Correcting the error will result in additional tax liability for the client. The mistake does not appear to have been intentional and it is unlikely that the IRS will ever detect the error. You have basically two choices : (1) You could ignore the error. (2) You could notify the client of the error.

Would you notify the client of the error? Yes No

4. In preparing your client's income tax return this year, you discover that the return you prepared last year for this client contained a material error. In particular you listed a $\$ 1,000$ deduction as a $\$ 3,000$ deduction. Correcting the error will result in additional tax liability for the client. The mistake was not intentional and it is unlikely that the IRS will ever detect the error. You have basically two choices: (1) You could ignore the error. (2) You could notify the client of the error.

Would you notify the client of the error? Yes No 
5. One of your clients is a well-connected executive in a large firm. You want to maintain a good relationship with this client in the hopes of future business referrals. Your new client has presented information to you in a relationship to the preparation of his income tax return. Some of the information appears to be incorrect, and you suspect that your client is attempting to reduce his tax liability inappropriately. You have basically two choices :

(1) You could go ahead and prepare the tax return according to the client's representation.

(2) You could first inquire about the correctness of the information.

Would you inquire about the correctness of the information? Yes No

6. One of your most important clients has strongly suggested that you change the treatment of an item on his income tax return. You believe that the treatment of the item suggested by the client will materially understate the client's correct tax liability. Further, there is no reasonable basis for the change. You have basically two choices: (1) You could refuse to change the item. (2) You could agree to change the item as suggested by the client.

Would you agree to change the item?

Yes No

Edward Monsour is Assistant Professor of Accounting at California State University, Los Angeles. He received his J.D. from Cleveland-Marshall College of Law and he is a CPA. His research has been published in Business Journal of Entrepreneurs and many national and regional conference proceedings. His research interests are in the areas of taxation, accounting ethics and education.

Rafik Z. Elias is Associate Professor of Accounting at California State University, Los Angeles. He received his DBA in accounting from Louisiana Tech University and he is a CPA. His research has been published in Advances in Accounting, Journal of Business Ethics, Advances in Public Interest Accounting, Research on Accounting Ethics, and many conference proceedings. His research interests are in the areas of auditing, accounting ethics and education.

Cheryl A. Cruz is currently Associate Dean, Undergraduate Studies and Professor of Tax and Accounting at California State University, Los Angeles. She earned her J.D. from University of California, Los Angeles, and she is a CPA. Her research has been published in Journal of Business Ethics, Journal of Business and Management and Journal of the Academy of Business Administration. Her research interests are in the areas of taxation and ethics. 